\title{
How Would Medicare for All Affect Physician Revenue?
}

\author{
Christopher Cai, MD
}

Department of Medicine, Internal Medicine Residency Program at Brigham and Women's Hospital, Harvard Medical School, Boston, MA, USA.

J Gen Intern Med 37(3):671-2

DOI: $10.1007 / \mathrm{s} 11606-021-06979-Z$

(C) Society of General Internal Medicine 2021

$\mathrm{O}$ rganized medicine in the USA is shifting its position toward single-payer reform, one version of which, "Medicare for All," has gained substantial support in Congress. The American Medical Association recently left the Partnership for America's Healthcare Future, a lobbying group that spent more than one hundred million dollars annually opposing both a public option and Medicare for All in federal election campaigns. In 2020, the American College of Physicians and the Society of General Internal Medicine went a step further, endorsing both public option and single-payer reforms.

Yet, physician opinion on Medicare for All remains split, with most doctors concerned that such reform might decrease their income. While physicians are highly paid, these concerns are understandable given the burden of student debt, the length of medical training, and Medicare's lower fees relative to private insurers'.

Are such concerns supported by evidence? The nonpartisan Congressional Budget Office (CBO) recently estimated payments to physicians in 2030 under current policies and five options for Medicare for All. It projects that without reform the weighted average of public and private payments to physicians will increase to $116 \%$ of the 2019 weighted average, versus between $108 \%$ and $117 \%$ under the various Medicare for All options analyzed. ${ }^{1}$ But because the $\mathrm{CBO}$ expects Medicare for All to increase society-wide utilization of care, it also predicts that providers' total revenues would increase, even if fee levels were to decline.

More specifically, the CBO projects that in 2030 providers' total outpatient revenues would be between 5 and $9 \%$ higher under Medicare for All than without reform; physician services currently account for $78 \%$ of such revenue. ${ }^{1,2}$ These estimates assume that Medicare for All would not significantly alter the supply of physicians, which is currently limited by the supply of residency and medical school spots. ${ }^{1}$

Received April 29, 2021

Accepted June 9, 2021

Published online July 8, 2021
Some scholars project even larger boosts to physicians' take-home pay because the CBO estimates may understate practices' savings from streamlined billing. If, as studies suggest, Medicare for All would free up roughly 5\% of doctors' work hours currently spent on billing, allowing them to increase patient care, per-physician revenue could rise by between $\$ 39,816$ and $\$ 157,412$ annually. ${ }^{2}$ While those figures may be an overestimate, since some providers might choose to spend the freed-up time on leisure activities rather than increased patient care, they may underestimate revenue changes, as fee-for-service providers have, in the past, responded to decreased Medicare reimbursement rates by increasing volume of services. ${ }^{1}$ The latter won't apply to salaried providers, such as those working in capitated healthcare systems, but these providers are still likely to feel the benefits of administrative streamlining.

Other prominent economic analyses of Medicare for All have also projected net increases in physicians' revenue, even if current Medicare payment rates do not increase. ${ }^{3}$ Yet despite projecting increases in physicians' revenues, almost all estimates of the overall costs of single-payer reform project savings, due to savings from administrative simplification. ${ }^{3}$ Hence, it appears possible to design a single-payer reform that would offer universal coverage without cost sharing, while increasing net revenue to providers and decreasing national health expenditures. ${ }^{3}$

History offers hopeful messages about the likely effect of single-payer reform on doctors' incomes. When Canada transitioned to single-payer in the mid-20th century, physician income increased, and physicians remained the highest paid professionals in the nation. ${ }^{4}$ Since then, physician income in Canada has grown faster than the incomes of other workers. Yet, caution is warranted in interpreting these trends, which may not be duplicated in a reform initiated five decades or more after Canada's system was fully implemented in 1971. Medicare's history offers mixed lessons. Limitation on increases in Medicare's payments to physicians (known as the sustainable growth rate or SGR) included in the 1997 Balanced Budget Act threatened sharp cuts in Medicare's fee schedule. Yet Congress annually overrode the threatened cuts, and eventually repealed the SGR formula.

How would increases in revenue projected by the $\mathrm{CBO}$ be distributed among various physician specialties? Since both Congressional Medicare for All bills provide comprehensive benefits with little or no cost sharing (copayments or deductibles), individuals who currently cannot get medical care 
because of cost would increase their utilization of care. As a result, doctors who serve patients who are undertreated at present may experience the greatest increases in demand for their services, and in their revenues. Primary care providers are likely to fall into this category, given the degree to which hypertension, diabetes, hyperlipidemia, and other chronic conditions are currently undertreated. Anticipating this, the Congressional legislation would set aside funding to establish an Office of Primary Care, charged with developing policies to increase the number of primary care practitioners.

Although primary care doctors might get the biggest income boosts under single payer, specialists would continue to be high earners. The 1966 implementation of Medicaid/ Medicare resulted in an increase in per-capita surgical procedures among the elderly. ${ }^{5}$ In Canada, the specialist:primary care income ratio has remained quite high; in 2019, gross clinical payments to thoracic surgeons averaged $\$ 588,000$ (Canadian dollars) compared to $\$ 280,000$ for family medicine physicians. Malpractice insurance costs, currently the highest for proceduralists, would likely fall as they did in Canada, since patients would no longer have to sue to cover future medical costs. And in many doctors' practices, the case mix is likely to change for the better. As patients with unmet medical needs increase their utilization, the limited supply of hospital beds and physicians would likely cause a modest decrease in the delivery of low-value services. ${ }^{5}$ In essence, doctors could shift their efforts to address the greatest needs, without fear of losing income. To prevent waitlists, an increase in residency training programs may be necessary.

Medicare for All may also decrease inequities in physician pay. Increased demand and federal funding for primary care may modestly mitigate the racial and gender pay gaps in medicine, as nonwhite and non-male physicians are more likely to specialize in primary care fields. ${ }^{6}$ In addition, using a funding scheme called "global budgeting," Medicare for All would likely increase revenue for underfunded safety net hospitals and clinics, which disproportionately employ physicians of color. ${ }^{7}$ However, the root causes of such pay disparities are racism and sexism, and thus, even with Medicare for All, additional anti-racist and anti-sexist reforms will be needed in the workplace.

Proposals for a Medicare "public option" or "Medicare Advantage for All" would sacrifice most of the administrative savings that Medicare for All could garner, making universal first dollar coverage unaffordable, minimizing increases in the utilization of care, and hence physicians' practice revenues. Additionally, current fee schedules would likely persist under a public option reform, preserving the status quo that offers outsized rewards for performing procedures and caring for privately insured patients.

In sum, the available evidence-including the CBO's authoritative estimate - suggests that physicians would prosper under single-payer reform. By supporting Medicare for All, physicians - and organized medicine - can get a twofer: acting in physicians' self-interest while advancing legislation that would be enormously beneficial to patients.

\section{Acknowledgements:}

Contributors: I am grateful for the feedback of Dr. Steffie Woolhandler, Dr. David Himmelstein, Dr. Samuel Dickman, Dr. Iris Borowsky, and Dr. Steve Borowsky on previous versions of this manuscript.

Corresponding Author: Christopher Cai, MD; Department of Medicine, Internal Medicine Residency Program at Brigham and Women's Hospital, Harvard Medical School, Boston, MA, USA (e-mail: chrislcai@gmail.com).

\section{Declarations:}

Disclosures: Dr. Cai has previously worked as a paid summer health policy fellow for US Representative Pramila Jayapal, the lead cosponsor of the Medicare for All Act of 2021, as a paid summer researcher for Physicians for a National Health Program (PNHP), a nonprofit which favors single-payer health reform, and as an unpaid board member of Students for a National Health Program (SNaHP) and PNHP.

\section{REFERENCES}

1. How CBO Analyzes the Costs of Proposals for Single-Payer Health Care Systems That Are Based on Medicare's Fee-for-Service Program: Working Paper 2020-08 [Internet]. Congressional Budget Office; [cited 2021 Jan 30]. Available from: https://www.cbo.gov/publication/56898

2. Gaffney A, Woolhandler S, Himmelstein D. Congressional Budget Office Scores Medicare-for-All: Universal Coverage for Less Spending [Internet]. Health Affairs Blog. February 16 2021. Available from: https://www. healthaffairs.org/do/10.1377/hblog20210210.190243/full/

3. Cai C, Runte J, Ostrer I, Berry K, Ponce N, Rodriguez M, et al. Projected costs of single-payer healthcare financing in the United States: a systematic review of economic analyses. PLoS Med 2020;17(1):e1003013.

4. Duffin J. The impact of single-payer health care on physician income in Canada, 1850-2005. Am J Public Health 2011;101(7):1198-208.

5. Gaffney A, McCormick D, Bor D, Woolhandler S, Himmelstein D. Coverage Expansions and utilization of physician care: evidence from the 2014 Affordable Care Act and 1966 Medicare/Medicaid Expansions. Am J Public Health 2019;109(12): 1694-701.

6. Medscape 2020 Physicians' Compensation Report [Internet]. [cited 2021 Feb 5]. Available from: https://www.medscape.com/slideshow/2020-compensation-overview-6012684\#12

7. Cai C, Kahn J. Medicare for All Would Improve Hospital Financing [Internet]. Health Affairs Blog 2019. Available from: https://www. healthaffairs.org/do/10.1377/hblog20191205.239679/full/

Publisher's Note: Springer Nature remains neutral with regard to jurisdictional claims in published maps and institutional affiliations. 